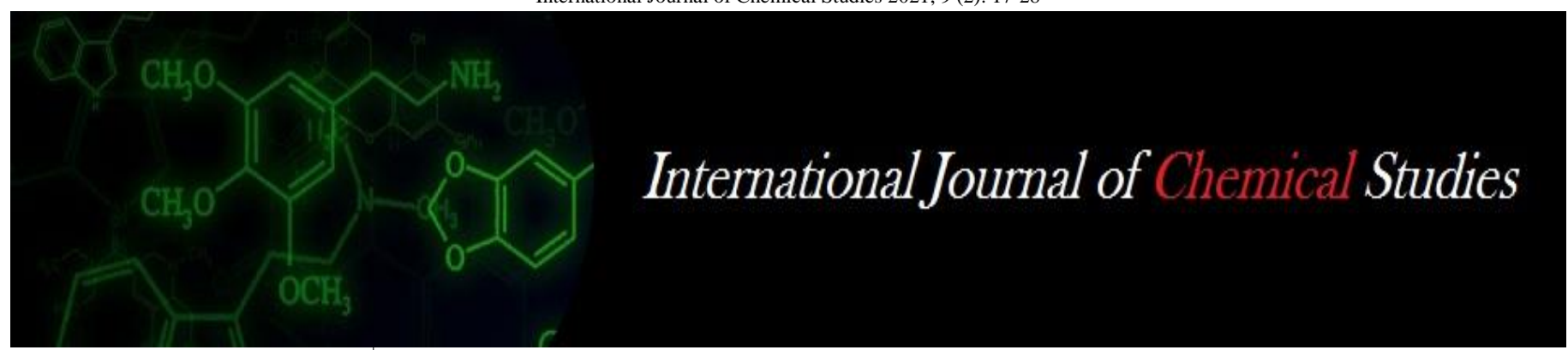

P-ISSN: 2349-8528

E-ISSN: 2321-4902

www.chemijournal.com

IJCS 2021; 9 (2): 17-28

(C) 2021 IJCS

Received: 11-01-2021

Accepted: 18-02-2021

Nur'Ain Najwa Mohd Nor Halal Products Research

Institute, Universiti Putra

Malaysia, 43400 UPM Serdang,

Selangor, Malaysia

Nazrim Marikka

National Institute of

Fundamental Studies Hanthana

Road, Kandy, Sri Lanka

Yanty Noorzianna Manaf Halal Products Research

Institute, Universiti Putra

Malaysia, 43400 UPM Serdang,

Selangor, Malaysia

Shuhaimi Mustafa

a. Halal Products Research

Institute, Universiti Putra

Malaysia, 43400 UPM

Serdang, Selangor, Malaysia

b. Department of Biochemistry and Microbiology, Faculty of Biotechnology and

Biomolecular Sciences,

Universiti Putra Malaysia, 43400 UPM Serdang, Selangor, Malaysia
Corresponding Author:

Nazrim Marikkar

National Institute of

Fundamental Studies Hanthana

Road, Kandy, Sri Lanka

\section{Chemical characteristics, physical and functional properties of some $\beta$-bonded polysaccharides: A review}

\author{
Nur’Ain Najwa Mohd Nor, Nazrim Marikkar, Yanty Noorzianna Manaf \\ and Shuhaimi Mustafa
}

DOI: https://doi.org/10.22271/chemi.2021.v9.i2a.11991

\begin{abstract}
$\beta$-bonded polysaccharides are biopolymer substances used as functional ingredients that provide nutritional benefits and health implications. They are extracted from several sources which include higher plants, yeasts, fungi, etc. Applications of $\beta$-bonded polysaccharides cover a wide range of benefits, which include new sensorial properties, texture, less use of fat, and improvement to gut health. Incorporation of $\beta$-bonded polysaccharides in food formulations is set to grow worldwide and some of them are already used as food ingredients. In this article, we attempted to review recent studies on chemical characteristics, functional properties, and therapeutic values of different $\beta$-bonded polysaccharides. Some gaps in knowledge that require further research are also highlighted.
\end{abstract}

Keywords: Carbohydrates, $\beta$-bonding polysaccharides, gut health, prebiotics

\section{Introduction}

Polysaccharides are biopolymers occurring in the nature to perform various functions. They act as nature's energy reserves and form hydrated cross-linked three-dimensional network to give mechanical strength to plant tissues. Starch, glycogen and plant gums such as guar gum, gum Arabic and locust bean gum are some of the energy storage polysaccharides. There are several non-starch polysaccharides, which serve as principal components responsible for structure of the plant tissues. Cellulose is the most abundant cell wall polysaccharides, followed by hemicellulose and pectin ${ }^{[100]}$. These polysaccharides are a non- $\alpha$-glucan type that reach the human colon where they are indigestible by the human digestive tract enzymes. A variety of substances occurring in the nature including $\beta$-glucan, arabinoxylan, inulin, manaans, gums etc. fall under the category of $\beta$-bonded polysaccharides. $\beta$-glucan comprises of linear chain of $\beta$-D-glucopyranosyl units that are linked by $(1 \rightarrow 3)$ and $(1 \rightarrow 4)$ linkages ${ }^{\text {[94] }}$. Arabinoxylan is the next major component of the cell walls of wheat and rye and consists of a linear backbone of $(1 \rightarrow 4)$-linked $\beta$-D-xylopyranose units. The third most important example of $\beta$-bonded polysaccharides is inulin that consists primarily of $\beta$ - $(2 \rightarrow 1)$ fructosyl fructose units with a reducing end formed in an individual glucopyranose unit ${ }^{[89]}$. There are other polysaccharides types of animal origin, namely chitin, chitosan and glycosaminoglycans. Chitin is apparently a linear polymer of $\mathrm{N}$-acetyl-glucosamine units, which form covalent $\beta$ $(1 \rightarrow 4)$-linkages. According to reports, it is said to be a major component of the shells of crustaceans and some insects ${ }^{[104]}$. Chitosan, which is made by treating the chitin shells of shrimp and other crustaceans with an alkaline substance, is linear polymer of $\beta$ - $(1 \rightarrow 4)$-linked D-glucosamine and N-acetyl-D-glucosamine. Glycosaminoglycans are yet another type of long linear $\beta$-bonded polysaccharides consisting of repeating disaccharide units ${ }^{[23]}$. These are, however, exempted from the current focus due to over details of their subject matter. Over the years, several efforts have been made to study different aspects of $\beta$-bonded polysaccharides occurring in plant and microbial sources. All these have led to the accumulation of considerable amount of knowledge on their chemical structure, functional properties, nutritional benefits, etc. As this information are largely scattered in the literature, it has become a necessity to compile them in an orderly manner. Hence, a systematic review of the available literature detailing out the influence of chemical characteristics on the functional properties of different $\beta$-bonded polysaccharides is of great value for further advancement of research and product applications. 


\section{$\beta$-glucan}

\section{Extraction sources}

Cell walls of cereals (e.g. oat, barley), certain types of mushrooms (e.g. reishi, shiitake, Maitake), yeast, seaweed, and algae are the major sources of $\beta$-glucan ${ }^{[1]}$. According to Maheswari et al. ${ }^{[62]}$, both oats and barley are found to contain significant amount of $\beta$-glucan $[-3-5 \%$ (w/w, dry basis)] when compared to other major cereals. However, groat of some oat $(6-7 \%)$ and barley (12\%) cultivars might have much more. A lesser amount of beta-glucan could be found in other grain types such as wheat, rye, sorghum, etc. After evaluating ten different yeast strains, Pengkumsri et al. ${ }^{[76]}$ concluded that $\beta$ glucan yield recovery from various yeast strains might vary from 3.11 to $3.78 \%$. Apart from sources, method of extraction might also influence the yield of $\beta$-glucan. Recently, Maheswari et al. ${ }^{[62]}$ reviewed different $\beta$-glucan extraction methods employed for various grain sources mainly oats and barley. As per the analysis by this review, among the four classes of extraction methods namely aqueous, acidic, alkaline, and enzymatic, the recovery of $\beta$-glucan extracted were remarkably high only for aqueous and alkaline methods.

\section{Chemical structure}

Depending on the source of origin, the molecular weight (Mw) range of $\beta$-glucan might vary from ten to thousands of kilodaltons. Sources of origin, extraction protocol, including the solvents, reaction conditions, etc. are said to cause large variation in the $\mathrm{Mw}$ of $\beta$-glucan. The $\mathrm{Mw}$ differences might also affect the molecular conformations as for instance the $\beta$ - glucan with low Mw exhibits a random coiled conformation while those with high Mw exists either in single or triple helix conformations ${ }^{[34]}$. Cereal based $(1 \rightarrow 3)(1 \rightarrow 4)-\beta$-D-glucans contain $70 \%(1 \rightarrow 4)$-linked and $30 \%(1 \rightarrow 3)$ linked $\beta$-Dglucopyranosyl residues structured mainly in a sequence of $\beta$ $(1 \rightarrow 3)$-linked cellotriosyl and cellotetraosyl units (Figure 1). $\beta$-glucan of oats, barley, rye and wheat can be distinguished based on the differences in the ratios of major products of hydrolysis, 3-O- $\beta$-cellobiosyl-D-glucose and 3-O- $\beta$ cellotriosyl-D-glucose ${ }^{[98]}$. Cereal-based $\beta$-glucan might display significant diversity in their structures, including the ratio of tri- to tetramers, the amount of longer cellulosic oligomers and the ratio of $\beta-(1 \rightarrow 4): \beta-(1 \rightarrow 3)$ linkages ${ }^{[51]}$. Mixed linkages $(1 \rightarrow 3, \quad 1 \rightarrow 4)-\beta$-D-glucans are linear homopolymers of D-glucopyranosyl (Glcp) residues, which are linked mostly via two or three consecutive $\beta$ - $(1 \rightarrow 4)$ linkages that are separated by a single $\beta$ - $(1 \rightarrow 3)$ linkage (Figure 1) ${ }^{[52]}$. Presently, there is hardly any proof for appearance of two or more adjacent $\beta$ - $(1 \rightarrow 3)$ linkages in the $\beta$-glucan chains ${ }^{[27]}$. $\beta$-glucans extracted from oats, wheat, barley and rye are differentiated from lichenins through differences in the ratios of the major products of hydrolysis; 3 -O- $\beta$-cellobiosyl-D-glucose and 3-O- $\beta$-cellotriosyl-Dglucose ${ }^{[98]}$. A $(1 \rightarrow 3),(1 \rightarrow 4)$ - $\beta$-glucan-4-glucanohydrolase also known as lichenase would hydrolase the linkage of 3-Osubstituted glucose unit in the $\beta$-glucan. The products of the hydrolysis will be represented by the building blocks of native $\beta$-glucan ${ }^{[40]}$.

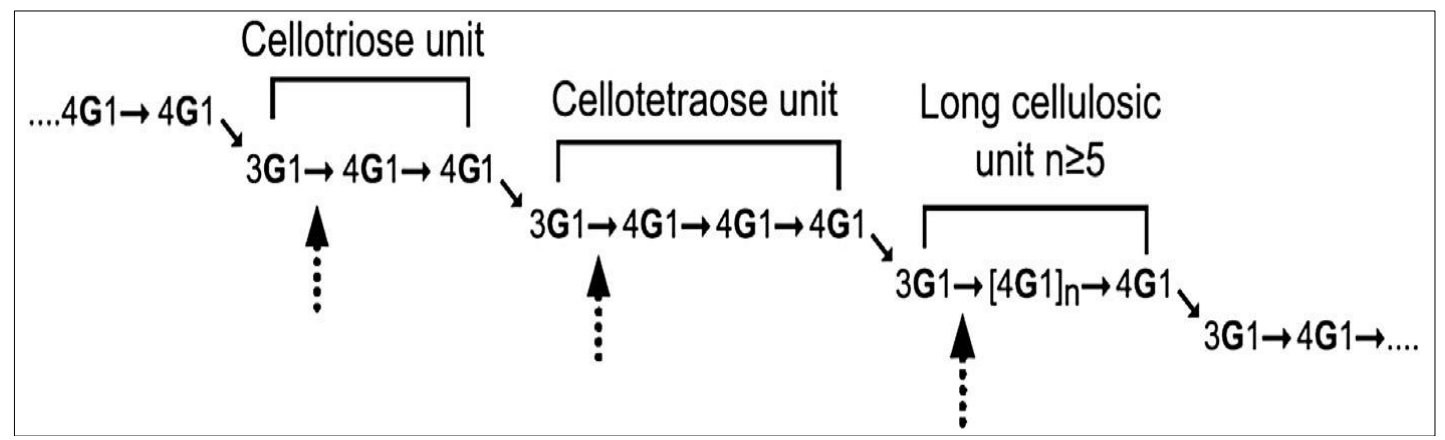

Fig 1: General molecular structure of $\beta$-glucan ${ }^{[44]}$

\section{Physical and functional properties}

Multiple functionalities and uses of $\beta$-glucan are mainly due to the mixed linkage $(1 \rightarrow 3)(1 \rightarrow 4)-\beta$-D-glucan $(\beta$-glucan $)$, which make it unique as a plant cell wall component and a source of dietary fiber ${ }^{[98]}$. Based on the sources of origin and macromolecular structure, $\beta$-glucan is said to exhibit significant differences in their properties ${ }^{[34]}$. The long chain of $\beta$-glucan is dominated by cellulose like $\beta 1 \rightarrow 4$ links, and interrupted every third or fourth glucose unit by a $\beta 1 \rightarrow 3$ linkage. This structural feature gives it a high-water binding capacity and ability to form high viscous solutions ${ }^{[34]}$. The presence of multiple-OH groups is also attributed to $\beta$ glucan's strong affinity towards water molecules. Among various physical properties, gelation is an important property of $\beta$-glucan. Generally, $\beta$-glucan's gelation rates are varied with $\mathrm{Mw}$ as for instance, the $\beta$-glucan of oat with low $\mathrm{Mw}$ displayed high gelation rates and short gelation times when compared to its high-Mw counterparts. The $\beta$-glucan with low Mw exhibiting increased gelation rate is said to be due to less spatial hindrance ${ }^{[61]}$. Some $\beta$-glucan were found to display antioxidant properties subject to $\mathrm{Mw}$ and source of origin. For instance, $\beta$-glucan of yeast with low $\mathrm{Mw}$ had higher antioxidant property Lei et al. ${ }^{[59]}$ while $\beta$-glucan from Chlorella pyrenoidosa with higher $\mathrm{Mw}$ exhibited better immune-stimulatory activity Suárez et al. ${ }^{[91]}$.

$\beta$-glucans can also function as hydrocolloids, which could contribute to gelling and thickening behavior in food systems ${ }^{[40]}$. Previous studies demonstrated that $\beta$-glucan samples with different $\mathrm{Mw}$ exhibited variations in their gelation rate. However, Doublier and Wood ${ }^{[33]}$ previously pointed out that the gel-forming properties of $\beta$-glucan with low $\mathrm{Mw}$ could also be influenced by the self-association via cellulose-like sequences. $\beta$-glucan has been used in different food formulations due to its water binding capacity and emulsion stabilizing properties to improve the textural and rheological properties ${ }^{[57]}$. The poor stability of bread can be improved by adding $\beta$-glucan to the flour mixture to increase the resting period in making quality doughs. Besides this, in all types of dough, it can also stimulate an increase in water absorption [87]. Generally, the high water absorbing capacity of $\beta$-glucan could suppress the amount of steam produced, resulting in the reduced loaf volume and greater crumb firmness ${ }^{[38]}$. 
Table 1: Sources, technological properties and health effects of $\beta$-bonded polysaccharides

\begin{tabular}{|c|c|c|c|c|}
\hline $\begin{array}{c}\text { Polysaccharide } \\
\text { type }\end{array}$ & Sources & Technological properties & Health and physiological effects & Reference \\
\hline$\beta$-glucan & $\begin{array}{l}\text { Cereals; mushrooms; } \\
\text { yeast; seaweed; algae }\end{array}$ & $\begin{array}{l}\text { Thickening and gelling behavior; } \\
\text { High water absorption capacity }\end{array}$ & $\begin{array}{l}\text { Remedial role in the etiology of colorectal } \\
\text { cancer; Reduced serum cholesterol levels; } \\
\text { Postprandial blood glucose control; Reduce } \\
\text { high blood pressure }\end{array}$ & $\begin{array}{c}{[6,13,18,22,32,39,40,52,54,} \\
56,58,72,86,88,99]\end{array}$ \\
\hline Inulin & $\begin{array}{l}\text { Chicory; Jerusalem } \\
\text { artichoke; wheat; } \\
\text { bananas; asparagus; } \\
\text { garlic; onion }\end{array}$ & $\begin{array}{l}\text { Sugar replacer; Fat replacer; } \\
\text { Texture modifier }\end{array}$ & $\begin{array}{c}\text { Improved bowel habitats; Enhance the growth } \\
\text { of bifidobacteria and lactobacilli and enhance } \\
\text { the gut environment; } \\
\text { In particulate form, possesses anti-cancer and } \\
\text { immune enhancing properties }\end{array}$ & $\begin{array}{c}{[9,10,12,17,20,26,29,30,37} \\
38,43,55,57,68,69,77,85,89, \\
95,101]\end{array}$ \\
\hline Arabinoxylan & $\begin{array}{l}\text { Millet; wheat; barley; } \\
\text { oat; rice; rye; } \\
\text { sorghum; maize }\end{array}$ & $\begin{array}{c}\text { Shelf-life extension; Rheological } \\
\text { properties of dough; } \\
\text { Improvement of bread loaf } \\
\text { volume; Retro-gradation of } \\
\text { starch } \\
\end{array}$ & $\begin{array}{l}\text { Reduction of serum cholesterol; Promoting } \\
\text { absorption of calcium and magnesium; Anti- } \\
\text { HIV activity; Increased T and B cell } \\
\text { proliferation; Immunomodulatory function }\end{array}$ & {$[35,41,44,53,66,78,90,103]$} \\
\hline Gum & $\begin{array}{l}\text { Endosperm of plant } \\
\text { seeds; plant exudates; } \\
\text { seaweeds; microbes }\end{array}$ & $\begin{array}{c}\text { Texture modifiers; Gelling } \\
\text { agents; Thickeners; Emulsifiers; } \\
\text { Stabilizers; Coating agents or } \\
\text { packaging films }\end{array}$ & $\begin{array}{c}\text { Reducing serum cholesterol level; Accelerating } \\
\text { wound healing; Strengthening the immune } \\
\text { system }\end{array}$ & {$[16,31,47,65,70,75,97]$} \\
\hline
\end{tabular}

\section{Health impact}

Several beneficial health influences of $\beta$-glucan have been compiled through various studies (Table 1 ). $\beta$-glucans can play aremedial role in in prevention of colorectal cancer due to the effects of increasing caecal and colon mass owing to the increasing resistance of starch digestion. This might vary depending on the quantity of fermentable material reaching the cecum. The high amount of fermentable material in the caecum will lead to an increased production of short chain fatty acids ${ }^{[28]}$. $\beta$-glucan is also capable of flatten the postprandial blood glucose level and proven to reduce serum cholesterol levels ${ }^{[17,97]}$. After studying the potential of oats to lower the cholesterol level, Anderson et al. ${ }^{[6-7]}$ reported that oat bran-rich in $\beta$-glucan could reduce the total serum cholesterol in hypercholesterolemic subjects by about $23 \%$ with minimal changes in HDL cholesterol level [6-7]. According to another study by Keenan et al. ${ }^{[56]}$, intake of whole grain cereals such as oats might lower the blood pressure.

The physiological effects of cereal-based $\beta$-glucan on type 2 diabetic subjects have been demonstrated through several previous studies. For instance, intake of both oat bran and cream of wheat plus oat gum meals significantly reduced the postprandial plasma glucose compared to the control diet of wheat ${ }^{[13]}$. Oat bran providing $7.3 \mathrm{~g}$ of $\beta$-glucan in a breakfast cereal was able to lower postprandial glucose in non-insulindependent diabetes mellitus (NIDDM) subjects than an oat bran breakfast cereal providing $3.7 \mathrm{~g} \beta$-glucan ${ }^{[52]}$. According to another study by Murphy et al. ${ }^{[72]}, \beta$-glucan is found to display immune-potentiation properties, but their connection to health benefit is not proven. Separately, Kahlon et al. ${ }^{[54]}$ stated that $\beta$-glucan could assist on improving blood glucose regulation as well as serum cholesterol reduction in diabetic and hypercholesterolemic patients due to their solubility in water and capacity to make a highly viscous solution.

\section{Inulin}

\section{Extraction source}

Inulin is a mixture of linear fructose polymer with different chain length and a glucose molecule at each $\mathrm{C} 2$ end. It occurs in many plant species, which include chicory, Jerusalem artichoke, wheat, bananas, asparagus, garlic, onion, etc. Inulin occurs in high amounts in the roots and tubers of chicory (15$20 \%)$, Jerusalem artichoke (14-19\%), dahlia (15-20\%), shatwaar (15-20\%), salsify (15-20\%), kuth (18-20\%), garlic $(9-16 \%)$ etc. ${ }^{[87]}$. Although root of chicory is the main source for commercial production of inulin ${ }^{[73]}$, use of Jerusalem artichoke and dahlia has been widely investigated. The conventional process of inulin extraction involves high thermal agitation $\left(70-80{ }^{\circ} \mathrm{C}\right)$ and prolonged extraction time (1-2 h). As large amounts of impurities are present in the juice extracted through the conventional process, further purification steps are required. As such, researchers looked into non-conventional technologies such as enzyme assisted extraction, ultrasound assisted extraction, microwave assisted extraction, supercritical fluid extraction, and pulsed electric fields as alternative environmental friendly methods [105]. Although these are said to be greener approaches when compared to the conventional method, their cost-effectiveness needs to be studied for their commercial viability.

\section{Chemical structure}

In the nature, inulin occurs as a polysaccharide consisting of fructose units which are linked with $\beta$ - $(2,1)$-D-fructosylfructose bonds of varying chain lengths with a glucose molecule at the end of each fructose chain (Figure 2) ${ }^{\text {[24] }}$. Inulin extracted from plants are known to have chains of 2100 or more fructose units. When compared to plant inulin, microbial inulin are found to have a larger degree of polymerization ranging from 10,000 to $100,000^{[84]}$. Garlic fructan, on the other hand, has a $(2,1)$-linked $\beta$-D fructosyl backbone with $(2,6)$-linked $\beta$-D-fructosyl side chain ${ }^{[14]}$. Native Dahlia inulin has longer chain than Chicory inulin, while Jerusalem artichoke inulin is known to have a much shorter chain ${ }^{[20]}$. In chicory, inulin has a degree of polymerization (DP) ranging from 3 to 60 monosaccharides units. Non-fractionated inulin extracted from fresh roots might contain glucose, fructose, sucrose and small oligosaccharides. Inulin from chicory roots can be modified chemically to yield shorter chain fractions known as fructooligosaccharides (FOS) ${ }^{[102]}$.

\section{Physical and functional properties}

The physical and functional properties displayed by inulin in food and pharmaceutical systems are strongly connected to their $\mathrm{Mw}$ and the nature of bonding. Occurrence of multiple hydroxyl groups in its chemical structure contributes greatly to its strong affinity towards water molecules. This 
characteristic feature helps in the formation of gel, which is a three-dimensional network of insoluble particles. This ensures physical stability as the liquid water.

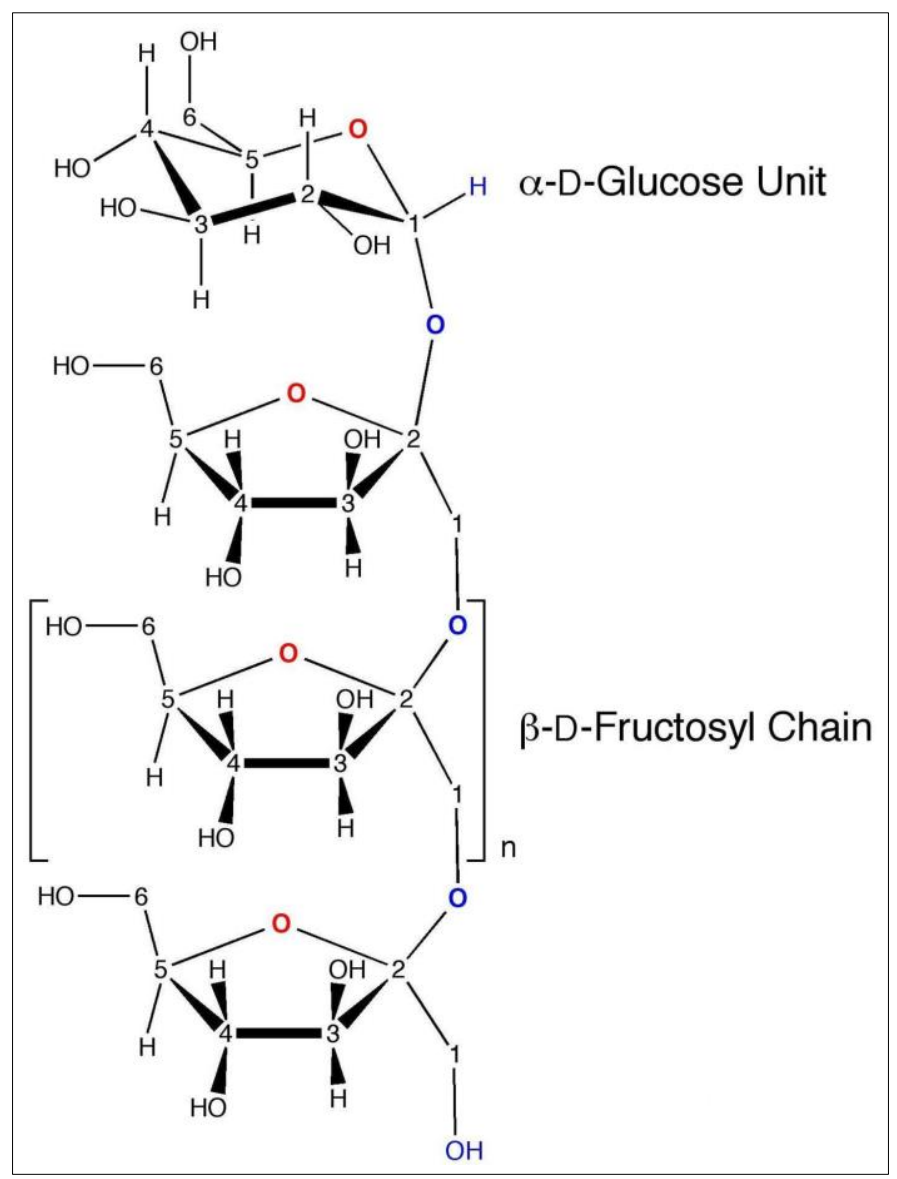

Fig 2: Inulin polymers ${ }^{[11]}$

becomes immobilized within these particles ${ }^{[21]}$. The unique drug delivery capability of inulin is due to stability and strength of the $\beta$ - (2-1) glycosidic linkages which can withstand to the extreme $\mathrm{pH}$ and ionic strength conditions in the human GI tract avoiding the action of endogenous enzymes ${ }^{[48]}$. There has been a growing interest among food industries for inulin due to its functional properties, which include fat replacement, sweetening synergies, rich soluble fiber, and enhancement of bowel health (Table 1) ${ }^{[20]}$. Apart from being a low-calorie sweetener, inulin contributes to bland neutral flavors, fat-like texture and mouth feel ${ }^{[95]}$. Potential applications of inulin to substitute sugar and fat include milk-based products, breakfast spreads, frozen desserts, chocolate and baked items ${ }^{[29]}$. Mixing of certain inulin-type probiotics with water could produce a potential fat replacer because the combination will have the same mouth feel and texture like a fat. However, it can only be used in water-based food products such as spreads and dairy products rather than dry foods ${ }^{[26]}$. High Performance (HP) inulin having high molecular weight and longer chain is mostly desired for application as fat replacers [55]. However, solubility of inulin-type fructans is reduced with longer chain length, resulting in the inulin microcrystals formation when mixing with water or milk. They have a smooth, creamy mouth feel, which are not discretely perceptible. Inulin HP has no sweetness contributions but it has almost twice the fat mimetic features of a standard inulin [55]. In baking application, addition of inulin has an effect on the rheological characteristics, water absorption capacity, and dough development. Addition of roughly $2.4-7.5 \%$ of inulin would decrease water absorption in the dough; this is more obviously seen with shorter chain inulin due to their lubricating effects on sugars and oligosaccharides present ${ }^{[77]}$. Meyer and Peters ${ }^{[68]}$ noticed that inulin with different degrees of polymerization has increased the dough stability. For instance, addition of 1 - 4\% inulin TEX (long chain length) has increased the dough development time and stability, resulting in strengthening of the dough.

\section{Health impact}

The prebiotic properties of inulin are well-recognized ${ }^{[05]}$ as it can influence the colonic microbiota, giving beneficial effects on human gut health (Table 1) ${ }^{[38]}$. Owing to the $\beta$ configuration of the anomeric carbon at $\mathrm{C}-2$ position of fructose monomers, inulin resists hydrolysis by human digestives enzymes in the small intestinal ${ }^{[30]}$. As a consequence, inulin can enhance the growth of lactobacilli and bifidobacteria, which help improve the gut environment [20]. A specific increase in bifidobacteria in human of all ages [69] are linked to physiological effects such as improving the bowel habitats, lowering of serum cholesterol, increasing the absorption of calcium, etc. In some food formulations, replacing certain cholesterol raising fatty acids through supplemental inulin has been shown to be beneficial in the management of hypercholesterolemia. Substituting fats or sugar partly by inulin could have a direct influence on serum lipids as well as reducing the calorific density of selected foods ${ }^{[29]}$.

The widening application of inulin in pharmaceutical fields is due to its $\beta(2-1)$ glycosidic bonds, which make it indigestible 
by enzymes present in humans and other higher animals ${ }^{[12]}$. According to studies conducted by Davidson et al. ${ }^{[29]}$, there was no increment of both total cholesterol (1.3\%) and lowdensity lipoprotein cholesterol (LDL-C) $(2.1 \%)$ during inulin intake while total cholesterol and LDL-C increased to $7.4 \%$ and $12.3 \%$, respectively during the control phase. Based on the study conducted among 18 subjects with Type II diabetes mellitus, daily intake of $8.0 \mathrm{~g}$ of fructo-oligosaccharides for 14 consecutive days was shown to lower the total blood cholesterol by $0.49 \mathrm{mmol} / \mathrm{L}(8 \%)$ and LDL-C by $0.44 \mathrm{mmol} / \mathrm{L}$ $(10 \%)^{[101]}$. All these findings suggest that consumption of insoluble dietary fiber might reduce serum total cholesterol and LDL-C in a subject ${ }^{[29]}$. Further to this, inulin can act as a slow release drug delivery medium ${ }^{[89]}$ as well as function as a stabilizer for protein and peptide-based drugs and vaccines ${ }^{[43]}$. Apart from a immune-modulator ${ }^{[85]}$, other interesting biological effects of being a potent complement pathway activator and anti-cancer agent were also evidenced from the intake of inulin ${ }^{[57]}$. Hence, they were able to suppress the growth of colon cancers in animal models. Complementary effects of tumor inhibition were also seen with fermentation products of inulin. Particularly, the formation of short chain fatty acids such as butyric and propionic acids is reported to inhibit the growth of colon cancer ${ }^{[12]}$. According to another report, dietary inulin can also suppress methylnitrosoureainduced mammary carcinogenesis in Sprague-Dawley female rats ${ }^{[92]}$.

\section{Arabimoxylan}

\section{Extraction sources}

Arabinoxylan (AX) serves as the structural polysaccharides in the cell walls of several plant including woods and cereal grains. Millet, wheat, barley, oat, rice, rye, sorghum, and maize are some of the well-known sources of AX. Total AX content of grains might vary from $1.37 \%$ in wheat flour to $29.86 \%$ in maize bran ${ }^{[74]}$. In the past, byproducts of the food industry such as sugar beet pulp, banana peels, cereal bran, corncobs, etc. have also been used for the extraction of AX. Although different methods are available for isolation of AX from various plant sources, aqueous or alkali treatments are quite frequently used.

\section{Chemical structure}

AX are branched heteroglycan made up of pentose sugars, arabinose and xylose. They are composed of a linear backbone of $\beta-(1 \rightarrow 4)$ linked D-xylopyranosyl residue $(X y l p)$, which are linked through $(1 \rightarrow 4)$ glycosidic linkages. $\alpha$-L-arabinofuranose units (Araf) are attached to some of the Xylp residue at O-3, O-4, and/or at both $\mathrm{O}-2,3$ positions ${ }^{[74]}$. This will result in four structural elements in the molecular structure of arabinoxylans: monosubstituted Xylp at O-2 or O3 with ferulic acid residue esterified, disubstituted Xylp O-2, 3 , and unsubstituted Xylp (Figure 3) ${ }^{[51]}$. Although arabinose residues are attached as single substituents, a small portion of oligomeric side chains containing two or more Araf linked via $1 \rightarrow 2,1 \rightarrow 3$, and $1 \rightarrow 5$ linkages have been reported for $\mathrm{AX}$ extracted from wheat and rye ${ }^{[51]}$. The distributions of arabinosyl substituents and the degree of the substitution along the xylan backbone are vital, since they can affect the capacity of AX to interact with each other or other polysaccharides. Thus, they can alter physical and functional properties of the macromolecules ${ }^{[51]}$. AX of wheatendosperm comprises of highly branched regions, where singly (C-3) or doubly (C-2, 3) substituted xyloses are separated by singly unsubstitued xylose residues [42]. Generally, most highly branched xylan backbones are found in AX of rice compared to those extracted from barley, rye, and wheat. Other than this, they may also contain glucuronic acid moieties and galactose along with pentose sugar. The most important factor in determining physiochemical properties of $\mathrm{AX}$ are the degree and the distribution of side chain ${ }^{[46]}$. Unsubstituted xylose residue that segmented continuously permit intermolecular realignments and interchain associations ${ }^{[51]}$.

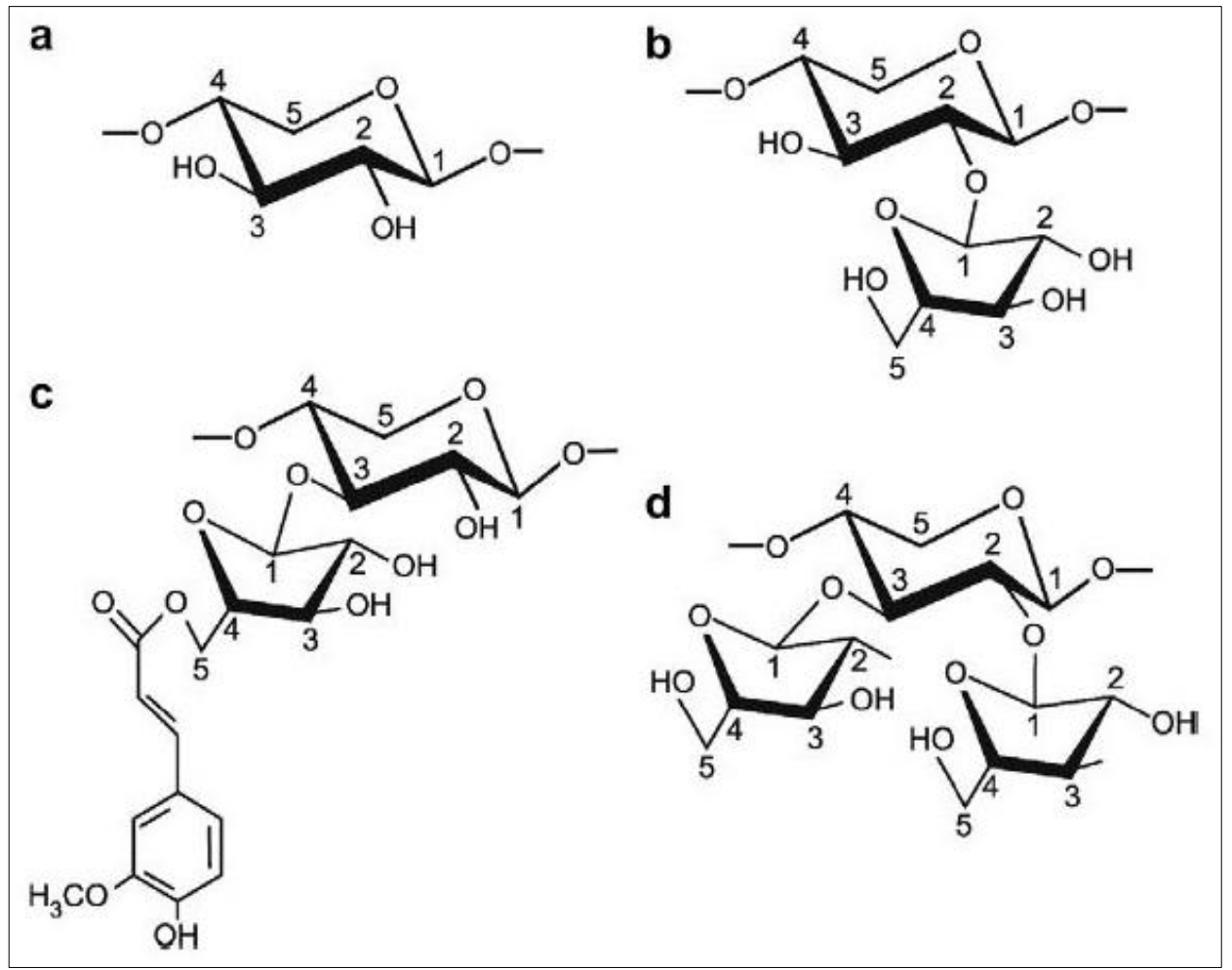

Fig 3: Structural elements present in arabinoxylans: (a) unsubstituted Xylp; (b) monosubstituted Xylp at O-2; (c) monosubstituted Xylp at O-3 with ferulic acid residue esterified to Araf and (d) disubstituted Xylp at O-2, $3^{\text {[51] }}$ 


\section{Physical and functional properties}

Arabinoxylan (AX) drew attention of several researchers owing to their role in improving physical properties of food systems. The Mw, substitution pattern, the xylose to arabinose ratio, amount and sequence of glycosidic bonds, and presence of other substituents would normally influence the physicochemical properties of $\mathrm{AX}{ }^{[81]}$. Apart from arabinose and xylose, some residues of galactose and glucuronic acid could also be found as side branches in the main chain of AX. According to $\mathrm{Li}$ and $\mathrm{Du}{ }^{[60]}$, the molecular characteristics of AX could also be influenced by genetics as well as isolation techniques. Most AX from wheat endosperm are water extractable but result in highly viscous aqueous solutions ${ }^{[25]}$. In aqueous solution, they are presumed to have a wormlike structure, which characterize their behavior as semi-flexible polysaccharides ${ }^{[51]}$. Presence of covalent-linkages between side chains of $\mathrm{AX}$ are believed to be responsible for higher water solubility ${ }^{[51]}$. Generally, changes of concentration and molecular weight of the polymers would influence the viscosity of the AX solution ${ }^{[82]}$. Hydrolysis of arabinoxylan by endoxylanase might alter its chemical structure and $\mathrm{Mw}$ causing changes in its solubility and viscosity. The main reason was the fact that xylanase was able to degrade AX to small oligosaccharides ${ }^{[79]}$. There are several interesting technological properties of AX, which have been beneficially used by food industries (Table 1). AX may be incorporated into foods to add nutritional enhancement or improving quality in terms of shelf life stability ${ }^{[90]}$. They were found to impart beneficial effect on bakery products because of their high-water absorbing capacity and ability to form hydrated networks ${ }^{[53]}$. They not only affect the retrogradation of starch, but also might influence moisture distributions, rheological properties of dough, and the loaf volume of bread ${ }^{[53]}$. AX may also be incorporated into pharmaceutical products owing to their interesting biological activities such as prebiotic, antioxidant, and anticancer properties ${ }^{[67]}$. The demonstrated antioxidant properties of AX are attributed to the high ferulic acid content in their molecular structure. Other than this, there is possibility of cumaric acid residues being esterified to arabinose units at the $\mathrm{O}-5$ position.

\section{Health impact}

Arabinoxylan (AX) could have physiological effect similar to that of $\beta$-glucans upon consumption by human ${ }^{[52]}$. According to Table 1, a host of beneficial functional properties of $\mathrm{AX}$ are demonstrated through research work. Several studies previously reported the physiological effects of arabinoxylans from wheat, rye and maize on cecal fermentation including production of short chain fatty acids, reduction of serum cholesterol and improvement of absorption of calcium and magnesium ${ }^{[66]}$. Farhan et al. ${ }^{[35]}$ stated that AX displayed their ability to form viscous solutions, which might slow down the rate of digestion in monogastrics. As they are indigestible in the small intestine, they could provide fermentable carbon sources to bacteria living in the large intestine ${ }^{[44]}$. Some other in vitro studies also indicated that a specific concentrate of long-chain water-extractable AX (LC-AX) could stimulate specific intestinal microbes such as Bifidobacterium longum [78]. According to some studies, a modified AX such as BioBran/MGN-3, acted as a potent biological response modifier (BRM), exhibiting anti-HIV activity, which helped to increase $\mathrm{T}$ and $\mathrm{B}$ cell proliferation and NK immunomodulatory function. BioBran/MGN-3 also notably influence the macrophage activity. The researchers first studied the intestinal microbiota in children by investigating the degradation of cross linked and non-cross linked AX. According to reported findings, ferulic acid cross-linking reduced the rate of $\mathrm{AX}$ fermentation. A modified $\mathrm{AX}$ from rice bran was a potent inducer of phagocytic function by macrophage but the effects were dependent on the type of macrophages and the concentration of the BioBran/MGN-3 [41].

\section{Gums}

\section{Extraction sources}

Gums are non-starch water-soluble polysaccharides with considerable commercial interest. Depending on the source of extraction, gums broadly categorized as exudate and nonexudate gums. When used as ingredients in processed foods, they are sometimes called hydrocolloids [15]. Gum Arabic, gum ghatti, fenugreek gum, gums of guar and locust bean etc. are polysaccharides of considerable commercially importance. They originate from different sources such as the endosperm of plant seeds (e.g. guar gum, fenugreek gum, locust bean gum), plant exudates (e.g. gum Arabic), seaweeds (e.g. agar), and bacteria (e.g. Xanthan gum) ${ }^{[5]}$. Different geographical regions of world are famous for production of these gums and their prices are generally affected due to fluctuations in demand and supply. Africa is World's largest supplier of GA, mostly of them come from Sudan $(80 \%)$ and throughout the Sahel, from Senegal to Somali. In the case of guar gum, India $(80 \%)$ is the world's largest producer, followed by Pakistan $(15 \%)$ and some other Asian countries. After studying three Indian guar cultivars, Sharma et al. ${ }^{[83]}$ stated that the gum extraction yields of G 80, HG 365, and Ageta 112 were 41.19, 37.32 , and $31.19 \%$, respectively. Extraction of gums from non-conventional sources such as fenugreek and durian seeds was an interest for some research groups. When defatted fenugreek seeds were subjected to extraction of gum at $10{ }^{\circ} \mathrm{C}$ for $2 \mathrm{~h}$, it was found to give a yield of $22 \%{ }^{[19]}$. Gum extracted from fenugreek seeds is already well-known for their properties and utilization in various food and pharmaceutical products [63]. According to another report, Amid and Mirhosseini ${ }^{[5]}$ succeeded in extracting gum from durian seeds thrown away in abundance after consumption. The researchers stated that under the optimal condition of extraction, the yield of gum from durian seed was found to be $56 \%$.

\section{Chemical structure}

The chemical structure of GA is complex; being a mixture of polyelectrolytes associated with calcium, magnesium and potassium salts, GA consists of both proteins and polysaccharides subunits. The backbone of GA is composed of 1,3-linked $\beta D$-galactopyranosyl units. The side chains are mainly composed of two to five 1, 3-linked $\beta \mathrm{D}$ galactopyranosyl units, joining to the main chain by 1 , 6linkages. $\alpha$-L-arabinofuranosyl, $\alpha$-L-rhamnopyranosyl, and $\beta$ D-glucopyranosyl units are present in their main and side chains ${ }^{[49]}$. Gum ghatti has very complex arrangements of neutral sugar units consists of Galp, Araf, and Arap and GlcA. They are attached to a molecular core of alternating $\beta$-D-GlcA and D-Man residues, the former linked through O-4 and the latter through O-2 (Figure 4). 


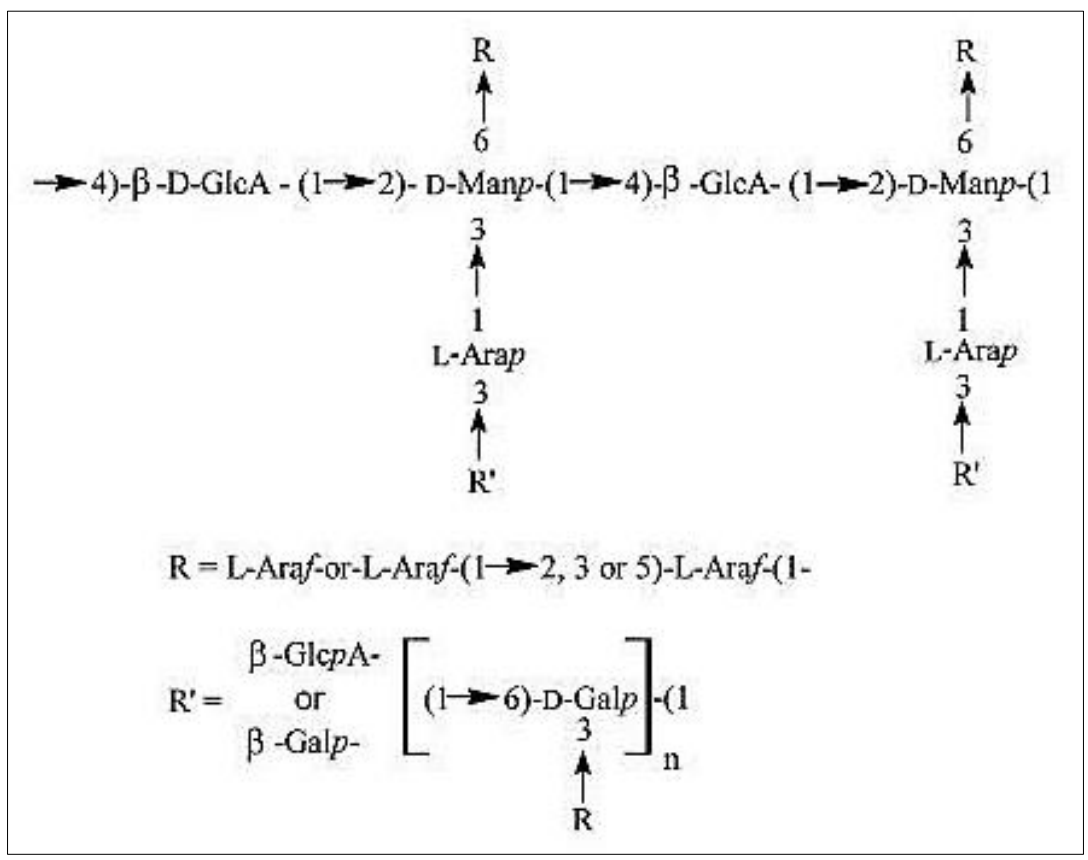

Fig 4: Structural features of gum ghatti ${ }^{[11]}$

D-Man residues are present as double branch-point of $(1,3)$ and $(1,6)$-linked Gal units that occupy the side chains. According to Tischer et al. ${ }^{[93]}$, the substituents at O-4 of the GlcpA- units were comprised of $6 \%$ of rhamnose in the polysaccharides. As a common feature of many plant gum polysaccharides, it contributes substantially to its structure as an $\alpha$-Rhap- $(1 \rightarrow 4)-\beta$-GlcpA-group. Guar gum mainly consists of the high molecular weight polysaccharides of galactomannans which are linear chain of $(1 \rightarrow 4)$-linked $\beta$-Dmannopyranosyl units with $(1 \rightarrow 6)$-linked $\alpha$-Dgalactopyranosyl residues as side chains ${ }^{[64]}$. Garti and Leser [36] stated that the mannose to galactose ratio of the units was $2: 1$. According to various other research studies, the ratio is found to be in the range of $1.6: 1$ to $1.8: 1$. Owing to greater branching of guar, it is reported to be known for greater hydrogen bonding and gelation activity. Locust bean gum resembles Guar gum as it being composed of the complex carbohydrate polymer of galactose and mannose, but with different proportions of these two sugars ${ }^{[64]}$. Xanthan being a gum of microbial origin has a hetero-polysaccharide with a very high molecular weight. Its main chain is made up of glucose units and the $\beta$-D-glucoses are linked $(1 \rightarrow 4)$ to form the backbone similar to cellulose. Its side chain consists of $\alpha$ D-mannose that contains an acetyl group, $\beta$-D-glucuronic acid, and a $\beta$-D-mannose terminal unit, linked to a pyruvate group.

\section{Physical and functional properties}

Gums are used for a variety of purposes such as gelling agents, texture modifiers, thickeners, emulsifiers, stabilizers, or as coating agents (Table 1) ${ }^{[65]}$. Water absorption and swelling are two essential characteristics of natural gums. Occurrence of plenty of hydroxyl groups in their molecular structure confers them the natural ability to form hydrogen bonds with water molecules, resulting in high viscosity of their aqueous solutions. According to Aphibanthammakit et al. ${ }^{[8]}$, the charged portion of the carbohydrate moiety of plant gums also contributes to viscosity because the dipolar water molecules participate in strong electro static interaction, leading to the formation of hydration shells. It is hypothesized that the strong water binding effects coming from their hydrophilic carbohydrate moiety of gums can prevent organoleptic defects in products like ice cream ${ }^{[45]}$.

According to multiple reports, plant gums were found to contain variable amounts of proteins ( 0.30 and $22.75 \%)$. Hydrophobic nature of the protein moieties adsorbs onto the surface of oil droplets while the hydrophilic carbohydrate moiety inhibits the flocculation and coalescence of molecules through electrostatic and stearic repulsions. The combination of highly branched polysaccharide chains and the affinity of the covalently linked protein moieties for the oil phase explain why some of the gums are excellent emulsifiers in oilin-water emulsions.

There has been a increasing trend in using GA as a food additive in bakery and confectionary products as well as drinks. According to Verbeken et al. ${ }^{[96]}$, GA has been used as thickener, stabilizer, and emulsifiers as it can effectively modify the rheological properties of aqueous food systems. For instance, incorporation of GA in frozen products like ice cream can prevent the undesirable formation of larger crystals. It is also used for the purpose of encapsulation, and coatings in pharmaceuticals. In pharmaceutical industry, it is used as an excipient, an adhesive, and binder in tableting. It is used in drinks due to such advantages as low viscosity, low calorie, and stabilizing property in oil in water emulsion. It is as good as inulin, with regard to prebiotic function.

Gum ghatti has several applications in food and pharmaceutical fields. They are excellent emulsifying agents because of the protenious molecular components that is bound to oil ${ }^{[47]}$. The high viscosity of the gum ghatti has been considered as an ideal characteristic feature to be used as a stabilizer for dense pharmaceutical emulsions and suspensions. As an emulsifying agent and stabilizer, gum ghatti has been widely used in beverages, butter containing table syrups, and flavor fixative for specific applications [31]. Unlike GA, Gum ghatti is not completely soluble at concentrations of $\geq 5 \%$ in water. The viscosity of gum ghatti dispersions increases with time, probably due to increases in the degree of aggregation of the polysaccharide molecules.

Guar seed endosperm is a source of water-soluble gum known as guar gum. Guar gum finds uses as an additive in bakery products, ice cream, yoghurt, sauces and sausages. In chapatti, 
pasta and bread making, it acts as a dough improver and texture improver. As a food additive, it emulsifies, binds water, prevents ice crystals in frozen products, moisturizes, thickens, stabilizes and suspends many liquid-solid systems. In industrial frying, it can be used to reduce the oil uptake by fried products. Guar gum found applications as thickener and stabilizer due to its ability to form hydrogen bonding with water molecule ${ }^{[64]}$. The ability to hydrate rapidly in cold water systems to give highly viscous solutions is the most significant characteristic of guar gum. In cheese making, guar gum has been successfully incorporated to produce low-fat cheese without changing the rheology and texture being compatible with full-fat cheese ${ }^{[64]}$.

\section{Health impact}

Gums from plant sources are known for their multifarious health implications (Table 1). Some researchers perceived the behavior of several plant gums during metabolism as similar to those of dietary fibre. Dietary fibre intake already found to minimize the risk of cardio vascular complications, help enhance immune function and weight management ${ }^{[45]}$. GA, for instance, is considered as a dietary supplement that can help in weight management and prevention of obesity. In normal experimental rats, it is reported to enhance the absorption of sodium in the small intestinal ${ }^{[80]}$. According to some other animal model studies, administration of GA was found to help maintain several blood lipid profile in both human ${ }^{[71]}$ and mice ${ }^{[1-2]}$. GA is also found to have the capability to alter the expression of mRNA levels of genes involved in lipid metabolism to suppress the diet-induced obesity ${ }^{[3]}$.

Guar gum and Gum ghatti are reported to play some significant role in the control and management of a number of health issues like chronic ailments and bowel related disorders. It might also be beneficially used for weight management and prevention of obesity. Guar gum can help to reduce serum cholesterol and postprandial blood glucose due to its gel forming properties. According to an in vitro study, Guar gum was found to significantly decrease the starch digestion as it can act as a barrier between starch and starch hydrolyzing enzymes ${ }^{[28]}$. Gum ghatti has been found to be effective in strengthening the immune system and reducing serum cholesterol level. As it helps in stimulating the immune system, it can reduce the effects of many neurological diseases. It has been found to be effective in patients undergoing chemotherapy to help prevent or lessen the side effects of the treatment. Apart from this, it also found to exert some influence to help reduce or slow down the ageing process and weight gaining.

\section{Conclusions and future prospects}

In this review, chemical structure, physical and functional properties and health impacts of $\beta$-bonded polysaccharides such as $\beta$-glucan, arabinoxylan, inulin, and selected gums have been discussed. Most of the studies provided evidence for multiple benefits of $\beta$-bonded polysaccharides in terms of functional and technological properties such as thickening and stabilizing property along with high water-holding capacities, which might help improve food texture and quality. Since some of these biopolymers are indigestible in small intestines, they will serve as substrate for partial fermentation in the large intestine, which will bring about physiological effects such as reducing cholesterol level, reducing postprandial blood glucose level, accelerating the wound healing, and strengthening the immune system. This review concluded that the properties and functions of individual $\beta$-bonded polysaccharides are strongly linked to their chemical structure and composition. It should be noted that there are further prospects and challenges in this field. For instance, the applications of some of the $\beta$-glucans are reported to be limited due to their high molecular weight and viscosity. In such cases, employment of emerging technologies of altering the molecular structure might be attempted to render improvement in their solubility. Introducing suitable ionic groups with appropriate degrees of substitution might be a good strategy to enhance the water solubility of $\beta$-glucans. Exploration of $\beta$-glucan and inulin from under-utilized grains and medicinal plants and other marine resources is a promising area. Particularly, investigation of the occurrence of $\beta$-bonded polysaccharides in microbial sources, thriving in marine environment, is an exciting area for new initiatives. Lack of biomedical expertise to identify and facilitate development is one of the impediments. Use of molecular and bioinformatics methods to explore the distribution of $\beta$ bonded polysaccharide producing bacteria in the marine environment can address this issue. Further, the tropical forest resources are known to provide ample opportunities for exploration of novel $\beta$-bonded polysaccharides. Particularly, there would be several forest species, which could yield exudate gums and their seeds might contain non-exudate gums. Profiling of their composition, bioactivities and functional properties could provide leads for future exploitation and developments.

\section{Author Contributions}

Nur'Ain Najwa Mohd Nor: Writing - Original Draft Preparation; Nazrim Marikkar: Conceptualisation, Writing Review \& Editing, Supervision; Yanty Noorzianna Manaf: Writing - Review \& Editing; and Shuhaimi Mustafa Supervision, Project Administration, Funding Acquisition. All authors have read and agreed to the published version of the manuscript.

\section{Funding}

The authors are grateful for the financial support under the Research University Grant Scheme (RUGS) (Project No: 0502-12-2141RU) from Universiti Putra Malaysia, Serdang, Selangor, Malaysia.

\section{Conflicts of interest}

The authors declare no conflicts of interest.

\section{References}

1. Ahmed A, Kaleem M. $\beta$-Glucan as a Food Ingredient. In Biopolymers for Food Design, Grumezesue, A.M., Holban, A.M., Eds.; Academic Press 2018, 351-381. https://doi.org/10.1016/C2016-0-00686-1.

2. Ahmed AA, Fedail JS, Musa HH, Kamboh AA, Sifaldin AZ, Musa TH. Gum Arabic extracts protect against hepatic oxidative stress in alloxan induced diabetes in rats. Pathophysiology 2015;22:189-194. https://doi.org/ 10.1016/j.pathophys.2015.08.002.

3. Ahmed AA, Musa HH, Fedail JS, Sifaldin AZ, Musa TH. Gum Arabic suppressed diet induced obesity by alteration the expression of mRNA levels of genes involved in lipid metabolism in mouse liver. Bioact Carbohydr Diet Fibre 2016;7:15-20.

https://doi.org/10.1016/j.pathophys.2015.08.002.

4. Amid BT, Mirhosseini HQ. Effect of different purification techniques on the characteristics of 
heteropolysaccharide-protein biopolymer from durian (Durio zibethinus) seed. Molecules 2012;17:1087510892. https://doi.org/ 10.3390/molecules170910875.

5. Amid BT, Mirhosseini HQ. Optimization of aqueous extraction of gum from durian (Durio zibethinus) seeds: A potential low-cost hydrocolloids. Food Chem 2012;132:1258-1268. https://doi.org/10.1016/j.foodchem.2011.11.099.

6. Anderson JW, Gilinsky NH, Deakins DA, Smith SF, O'Neal DS, Dillon DW, Oeltgen PR. Lipid responses of hypercholesterolemic men to oat-bran and wheat-bran intake. Am. J Clin. Nutr 1991;54:678-83. https://doi.org/ 10.1093/ajen/54.4.678.

7. Anderson JW, Story L, Sieling B, Chen WJ, Petro MS, Story J. Hypocholesterolemic effects of oat-bran or bean intake for hypercholesterolemic men. Am. J Clin. Nutr 1984:40:1146-55.

https://doi.org/ 10.1093/ajcn/40.6.1146.

8. Aphibanthammakit C, Barbar R, Nigen M, Sanchez C, Chalier P. Emulsifying properties of Acacia senegal gum: Impact of high molar mass protein-rich AGPs. Food Chem X 2020;6:100090.

9. Archer BJ, Johnson SK, Devereux HM, Baxter AL. Effect of fat replacement by inulin or lupin-kernel fibre on sausage patty acceptability, post-meal perceptions of satiety and food intake in men. Br. J Nutr 2004;91:591599. https://doi.org/ 10.1079/BJN20031088.

10. Aryana KJ, Plauche S, Rao RM, McGrew P, Shah NP. Fat-free plain yogurt manufactured with inulins of various chain lengths and Lactobacillus acidophilus. J Food Sci 2007;72:M79-84. https://doi.org/10.1111/j.1750-3841.2007.00302.x.

11. Aspinall GO, Hirst EL, Wickstrom A. Gum ghatti (Indian gum): The composition of the gum and the structure of the two aldobiouronic acids derived from it. J Chem. Soc 1955;0:1160-1165. https://doi.org/10.1039/JR9550001160.

12. Barclay T, Ginic-markovic M, Cooper Petrovsky P, Inulin N. A versatile polysaccharide with multiple pharmaceutical and food chemical uses. J Excip. Food Chem 2010;1:27-50.

13. Braaten JT, Wood PJ, Scott FW, Wolynetz MS, Lowe MK, Bradley-White P, Collins MW. Oat beta-glucan reduces blood cholesterol concentration in hypercholesterolemic subjects. Eur. J Clin. Nutr 1994;48:465-474.

14. Baumgartner S, Dax TG, Praznik W, Falk H. Characterization of the high-molecular weight fructan isolated from garlic (Allium sativum L.). Carbohydr. Res 2000;328:177-83. https://doi.org/10.1016/S0008-6215 (00)00097-5.

15. BeMiller JN. Gums and Related Polysaccharides. In B. O. Fraser-Reid, 2nd ed; Tatsuta, K., Joachim, T., Eds.; Glycoscience 2008, P1513-1533. https://doi.org/10.1007/978-3-540-30429-6_37.

16. Benhura MA, Chidewe C. Some properties of a polysaccharide preparation that is isolated from the fruit of Cordia abysinica. Food Chem 2002;76:343-347. https://doi.org/10.1016/S0308-8146 (01)00282-5.

17. Beriain MJ, Gomez I, Petri E, Insausti K, Sarries MV. The effects of olive oil emulsified alginate on the physico-chemical, sensory, microbial, and fatty acid profiles of low-salt, inulin-enriched sausages. Meat Sci 2011:88:189-197. https://doi.org/10.1016/j.meatsci.2010.12.024.
18. Brennan CS, Cleary LJ. The potential use of cereal $(1 \rightarrow 3,1 \rightarrow 4)-\beta$-d-glucans as functional food ingredients. J Cereal Sci 2005;42:1-13. https://doi.org/doi:10.1016/j.jcs.2005.01.002.

19. Brummer Y, Cui W, Wang Q. Extraction, purification and physicochemical characterization of fenugreek gum. Food Hydrocoll 2003;17:229-236. https://doi.org/10.1016/S0268-005X (02)00054-1

20. Causey JL, Feirtag JM, Gallaher DD, Tungland BC, Slavin JL. Effects of dietary inulin on serum lipids, blood glucose and the gastrointestinal environment in hypercholesterolemic men. Nutr Res 2000;20:191-201. https://doi.org/10.1016/S0271-5317 (99)00152-9.

21. César LP, Ana LLP, Claudia AS, José PU, Zenaida SL. Physical properties of inulin and technological applications. Polysaccharides 2014, 1-22. https://doi.org/10.1007/978-3-319-03751-6_80-1

22. Chen J, Raymond K. Beta-glucans in the treatment of diabetes and associated cardiovascular risks. Vasc Health Risk Manag 2008;4:1265-1272. https://doi.org/10.2147/vhrm.s3803

23. Chen JK, Shen CR, Liu CL. N-Acetylglucosamine: production and applications. Mar Drugs 2010;8:24932516. https:// doi:10.3390/md8092493

24. Chi ZM, Zhang T, Cao TS, Liu XY, Cui W, Zhao CH. Biotechnological potential of inulin for bioprocesses. Bioresour. Technol 2011;102:4295-303. https://doi.org/10.1016/j.biortech.2010.12.086.

25. Courtin CM, Delcour JA. Arabinoxylans and endoxylanases in wheat flour bread-making. J Cereal Sci 2002;35:225-243. https://doi.org/10.1006/jcrs.2001.0433.

26. Coussement PAA. Nutritional and health benefits of inulin and oligofructose inulin and oligofructose: safe intakes and legal status, J Nutr 1999;129:1412S-1417S. https://doi.org/10.1093/jn/129.7.1412S.

27. Cui W, Wood PJ, Blackwell B, Nikiforuk J. Physicochemical properties and structural characterization by two-dimensional NMR spectroscopy of wheat $\beta$-D-glucan - comparison with other cereal $\beta$-Dglucans. Carbohydr. Polym 2000;41:249-258. https://doi.org/10.1016/S0144-8617 (99)00143-5.

28. Dartois A, Singh J, Kaur L, Singh H. Influence of guar gum on the in vitro starch digestibility-rheological and microstructural characteristics. Food Biophys 2010;5:149-160. https://doi.org/10.1007/s11483-0109155-2.

29. Davidson MH, Maki KC, Synecki C, Torri SA. Effects of dietary inulin on serum lipids in men and women with hypercholesterolemia. Nutr. Res 1998;18:503-517. https://doi.org/10.1016/S0271-5317 (98)00038-4.

30. Delzenne NM, Roberfroid MR. Physiological effects of non-digestible oligosaccharides. LWT Food Sci. Technol 1994;27:1-6. https://doi.org/10.1006/fstl.1994.1001.

31. Deshmukh AS, Setty CM, Badiger AM, Muralikrishna KS. Gum ghatti: A promising polysaccharide for pharmaceutical applications. Carbohydr. Polym 2012;87:980-986. https://doi.org/10.1016/j.carbpol.2011.08.099.

32. Dongowski G, Huth M, Gebhardt E, Flamme W. Dietary fiber-rich barley products beneficially affect the intestinal tract of rats. J Nutr 2002;132:3704-3714. https://doi.org/10.1093/jn/132.12.3704.

33. Doublier JL, Wood PJ. Rheological properties of aqueous solutions of (1!3), (1!4) $\beta$-glucan from oats (Avena sativa L.). Cereal Chem 1995;72:335-340. 
34. Du B, Meenu M, Liu H, Xu B. A concise review on the molecular structure and functional relationship of $\beta$ glucan. Int. J Mol. Sci 2019;20:4032. https://doi:10.3390/ijms20164032.

35. Farhan S, Imran P, Faqir MA, Muhammed TS. Arabinoxylans and arabinogalactans: A comprehensive treatise. Crit. Rev. Food Sci. Nutr 2011;51:467-476. https://doi.org/10.1080/10408391003681418.

36. Garti N, Leser ME. Emulsification properties of hydrocolloids. Polym. Adv. Technol 2001;12:123-135. https://doi.org/10.1002/1099-1581 (200101/02)12:1/23.0.CO;2-0.

37. García ML, Cáceres E, Selgas MD. Effect of inulin on the textural and sensory properties of mortadella, a Spanish cooked meat product. Int. J Food Sci 2006;41:1207-1215. https://doi.org/10.1111/j.13652621.2006.01186.x.

38. Gibson GR, Probert HM, Loo JV, Rastall RA, Roberfroid MB. Dietary modulation of the human colonic microbiota: updating the concept of prebiotics. Nutr. Res. Rev 2004; 17:259-75. https://doi.org/10.1079/NRR200479.

39. Gill S, Vasanthan T, Ooraikul B, Rossnagel B. Wheat bread quality as influenced by the substitution of waxy and regular barley flours in their native and extruded forms. J Cereal Sci 2002;36:219-237. https://doi.org/10.1006/jcrs.2001.0458.

40. Ghotra BS, Vasanthan T, Temelli F. Structural characterization of barley $\beta$-glucan extracted using a novel fractionation technique. Food Res. Int 2008;41:957-963. https://doi.org/10.1016/j.foodres.2008.07.008.

41. Ghoneum M, Matsuura M. Augmentation of macrophage phagocytosis by modified arabinoxylan rice bran (MGN3/biobran). Int. J Immunopathol. Pharmacol 2004; 17:283-292. https://doi.org/10.1177/039463200401700308.

42. Goldschmid HR, Perlin AS. Interbranch sequences in the wheat arabinoxylan. Can. J Chem 1963;41:2272-2277. https://doi.org/10.1139/v63-329.

43. Hinrichs WL, Prinsen MG, Frijlink HW. Inulin glasses for the stabilization of therapeutic proteins. Int. J Pharm 2001;215:163-74. https://doi.org/10.1016/s0378-5173 (00)00677-3.

44. Huma BUA, Farhan S, Nazir A, Ali I, Bushra N, Muhammad A, Muhammad I, Tabussam T, Ahsan J. Functional and health-endorsing properties of wheat and barley cell wall's non-starch polysaccharides. Int. J Food Prop 2018;21:1463-1480. https://doi.org/10.1080/10942912.2018.1489837.

45. Hamdani AM, Wani IA, Bhat NA. Sources, structure, properties and health benefits of plant gums: A review. Int J Biol. Mac. Mol 2019;135:46-61. https://doi.org/10.1016/j.ijbiomac.2019.05.103.

46. Hopkins AM, DeSimone E, Chwalek K, Kaplan DL. 3D in vitro modelling of the central nervous system. Prog. Neurobiol 2013;70:1-25.1 https://doi.org/10.1016/j.pneurobio.2014.11.003.

47. Ido T, Ogasawara T, Katayama T, Sasaki Y, Al-Assaf S, Phillips GO. Emulsification properties of GATIFOLIA (Gum Ghatti) used for emulsions in food products. Food Ingredients J Jpn 2008;213:365-371.

48. Imran S, Gillis RB, Kok MS, Harding SE, Adams GG. Application and uses of inulin as a tool for therapeutic drug delivery. Biotechnol. Genet. Eng 2011;28:1-14.
49. Islam AM, Phillips GO, Sljivo A, Snowden MJ, Williams PA. A review of recent developments on the regulatory, structural and functional aspects of gum arabic. Food Hydrocoll 1997;11:493-505. https://doi.org/10.1016/S0268-005X (97)80048-3.

50. Izydorczyk MS, Dexter JE. Barley $\beta$-glucans and arabinoxylans: Molecular structure, physicochemical properties, and uses in food products-a Review. Food Res. Int 2008;41:850-868. https://doi.org/10.1016/j.foodres.2008.04.001.

51. Izydorczyk MS, Biliaderis CG. Cereal arabinoxylans: advances in structure and physicochemical properties. Carbohydr. Polym 1995;28:33-48. https://doi.org/10.1016/0144-8617 (95)00077-1.

52. Jenkins AL, Jenkins DJA, Zdravkovic U, Würsch $P$, Vuksan V. Depression of the glycemic index by high levels of beta-glucan fiber in two functional foods tested in type 2 diabetes. Eur. J Clin. Nutr 2002;56:622-628. https://doi.org/10.1038/sj.ejcn.1601367.

53. Justyna RK, Aleksandra K, Ewa N, Bartlomiej M. The influence of arabinoxylans on the quality of grain industry products. Eur. Food Res. Technol 2015;242:295303. https://doi.org/10.1007/s00217-015-2549-0.

54. Kahlon TS, Chow FI, Knuckles BE, Chiu MM. Cholestrol-lowering effects in hamsters of $\beta$-glucanenriched barley fraction, dehulled whole barley, rice bran, and oat bran and their combinations. Cereal Chem 1993;70:435-440.

55. Kelly G. Inulin-type prebiotics: a review. (Part 1). Altern Med Rev 2008;14:36-55.

56. Keenan JM, Pins JJ, Frazel C, Moran A, Turnquist L. Oat ingestion reduces systolic and diastolic blood pressure in patients with mild or borderline hypertension: a pilot trial. J Fam Pract 2002, 51.

57. Korbelik M, Cooper PD. Potentiation of photodynamic therapy of cancer by complement: the effect of gammainulin. Br. J Cancer 2007;96:67-72. https://doi.org/10.1038/sj.bjc.6603508.

58. Lazaridou A, Biliaderis CG. Molecular aspects of cereal $\beta$-glucan functionality: Physical properties, technological applications and physiological effects. J Cereal Sci 2007;46:101-118. https://doi.org/10.1016/j.jcs.2007.05.003.

59. Lei N, Wang M, Zhang L, Xiao S, Fei C, Wang X et al. Effects of low molecular weight yeast $\beta$-glucan on antioxidant and immunological activities in mice. Int. $\mathrm{J}$ Mol. Sci 2015;16:21575-21590.

60. Li J, Du J. Molecular characterization of arabinoxylan from wheat beer, beer foam and defoamed beer. Molecules 2019;24:1230. https://doi.org/10.3390/molecules24071230.

61. Li W, Wang Q, Yada RY. Studies of aggregation behaviours of cereal-glucans in dilute aqueous solutions by light scattering: Part I. Structure effects. Food Hydrocoll 2011;25:189-195.

62. Maheswari G, Sowrirajan S, Joseph B. Extraction and isolation of $\beta$-Glucan from grain sources- A review. J Food Sci 2017;82:1535-1545. https://doi.org/10.1111/1750-3841.13765.

63. Mathur V, Mathur NK. Fenugreek and other lesser known legume galactomannan-polysaccharides: Scope for developments. J Sci. Ind. Res 2005;64:475-481.

64. Mudgil D, Barak S, Khatkar BS. Guar gum: processing, properties and food applications- A review. J Food Sci. Technol 2014;151:409-418. 
https://doi.org/10.1007/s13197-011-0522-x.

65. McClements DJ. Food emulsions: Principles, practice and techniques, 2nd Ed.; CRC Press Boca Raton 2005.

66. Mendis M, Simsek S. Arabinoxylans and human health. Food Hydrocoll 2014;42:239-243. https://doi.org/doi:10.1016/j.foodhyd.2013.07.022.

67. Mendez-Encinas MA, Carvajal-Millan E, Rascon-Chu A, Astiazaran-Garcia HF, Valencia-Rivera DE. Ferulated arabinoxylans and their gels: Functional properties and potential application as antioxidant and anticancer agent. Oxid. Med. Cell. Long 2018, Article ID 2314759.

68. Meyer D, Peters B. Enhancing the nutritional value of bread with inulin. Agro Food Ind Hi Tech 2009;20:43-69.

69. Meyer D, Stasse-Wolthuis M. The bifidogenic effect of inulin and oligofructose and its consequences for gut health. Eur. J Clin. Nutr 2009;63:1277-1289. https://doi.org/10.1038/ejcn.2009.64.

70. Milani J, Maleki G. Hydrocolloids in food industry. In Food Industrial Processes-Method and Equipment; Valdez, B., Eds; Intech 2012, 1-23.

71. Mohamed RE, Gadour MO, Adam I. The lowering effect of gum Arabic on hyperlipidemia in Sudanese patients. Front Physiol 2015;6:160. https://doi.org/10.3389/fphys.2015.00160.

72. Murphy EA, Davis JM, Carmichael MD. Immune modulating effects of $\beta$-glucan. Curr. Opin. Clin. Nutr. Metab. Care 2010;13:656-661. https://doi.org/10.1097/MCO.0b013e32833f1afb.

73. Niness KR. Inulin and oligofructose: what are they? J Nutr 1999;129:1402S-1406S. https://doi.org/10.1093/jn/129.7.1402S.

74. Medina N, Carvajal-Millan G, Rascon-Chu EA, Marquez-Escalante JA, Guerrero V, Salas-Muñoz E. Feruloylated arabinoxylans and arabinoxylan gels: structure, sources and applications. Phytochem. Rev 2010;9:111-120. https://doi.org/10.1007/s11101-009-9147-3.

75. Osilesi O, Trout DL, Knight E. Hepatic responses to edible gums during refeeding of starved rats. J Nutr 1988;118;462-468. https://doi.org/10.1093/jn/118.4.462.

76. Pengkumsri N, Sivamaruthi BS, Sirilun S, Peerajan S, Kesika P, Chaiyasut K, Chaiyasut K. Extraction of $\beta$ glucans from Saccharomyces cerevisiae: Comparison of different extraction methods and in vivo assessment of immunomodulatory effect in mice. Food Sci. Technol 2017;37:124-130. https://doi.org/10.1590/fst.18217.

77. Peressini D, Sensidoni A. Effect of soluble dietary fibre addition on rheological and breadmaking properties of wheat doughs. J Cereal Sci 2009;49:190-201. https://doi.org/10.1016/j.jcs.2008.09.007.

78. Pieter VA, Tom VW, Sam P. Prebiotic effect and potential health benefit of arabinoxylans. Agro Food Ind. Hi Tech 2011;22:9-12.

79. Redgwell RJ, de Michieli JH, Fisher M, Reymond S, Nicolas P, Sievert D. Xylase induced changes to waterand alkali-extractable arabinoxylan in wheat flour: their role in lowering batter viscosity. J Cereal Sci 2001;33:8396.

80. Rehman KU, Wingertzahn MA, Teichberg S, Harper RG, Wapnir RA. Gum Arabic modifies paracellular water and electrolyte transport in the small intestine. Dig Dis Sci 2003;48:755-760.

https://doi.org/10.1023/a:1022845011192.

81. Rosicka J, Komisarczyk A, Nebesny E, Makowski B. The influence of arabinoxylans on the quality of grain industry products. Eur. Food Res. Technol 2016;242:295303. https://doi.org/10.1007/s00217-015-2549-0.

82. Saulnier L, Sado PE, Branlard G, Charmet G, Guillon F. Wheat arabinoxylans: Exploiting variation in amount and composition to develop enhanced varieties. J Cereal Sci 2007;46:261-281. https://doi.org/10.1016/j.jcs.2007.06.014.

83. Sharma P, Kaur A, Aggarwal P. Physicochemical, thermal, rheological, and morphological properties of flour from different guar seed (Cyamopsis tetragonoloba) cultivars. Int. J Food Prop 2017;20:1280-1289. https://doi.org/10.1080/10942912.2016.1207663.

84. Shoaib M, Shehzad A, Omar M, Rakha A, Raza H, Sharif HR et al. Inulin: properties, health benefits and food applications. Carbohydr. Polym 2016;147:444-454. https://doi.org/10.1016/j.carbpol.2016.04.020.

85. Silva DG, Cooper PD, Petrovsky N. Inulin-derived adjuvants efficiently promote both Th1 and Th2 immune responses. Immunol. Cell Biol 2004;82:611-616. https://doi.org/10.1111/j.1440-1711.2004.01290.x.

86. Sima P, Vannucci L, Vetvicka V. $\beta$-glucans and cholesterol (Review). Int. J Mol. Med 2018;1:1-10. https://doi.org/10.3892/ijmm.2018.3411.

87. Singh RS, Singh RP. Production of Fructooligosaccharides from Inulin by Endoinulinases and Their Prebiotic Potential. Food Technol. Biotechnol 2010;48:435-450.

88. Skendi A, Biliaderis CG, Papageorgiou M, Izydorczyk MS. Effects of two barley $\beta$-glucan isolates on wheat flour dough and bread properties. Food Chem 2010;119:1159-1167. https://doi.org/10.1016/j.foodchem.2009.08.030.

89. Stevens CV, Meriggi A, Booten K. Chemical modification of inulin, a valuable renewable resource, and its industrial applications. Biomacromolecules 2001;2:1-16. https://doi.org/10.1021/bm005642t.

90. Storsley JM, Izydorczyk MS, You S, Biliaderis CG, Rossnagel B. Structure and physicochemical properties of $\beta$-glucans and arabinoxylans isolated from hull-less barley. Food Hydrocoll 2003;17:831-844. https://doi.org/10.1016/S0268-005X (03)00104-8.

91. Suárez ER, Syvitski R, Kralovec JA, Noseda MD, Barrow CJ, Ewart HS et al. Immunostimulatory polysaccharides from Chlorella $\mathrm{p}$ yrenoidosa. A new galactofuranan. Measurement of molecular weight and molecular weight dispersion by DOSY NMR. Biomacromolecules 2006;7:2368-2376.

92. Taper HS, Roberfroid M. Influence of inulin and oligofructose on breast cancer and tumor growth. J Nutri. 1999;129:1488S-1491S. https://doi.org/10.1093/jn/129.7.1488S.

93. Tischer CA, Iacomini M, Wagner R, Gorin PAJ. New structural features of the polysaccharide from gum ghatti (Anogeissus latifola). Carbohydr. Res 2002;337:22052210. https://doi.org/10.1016/S0008-6215 (02)00296-3.

94. Tokár M, Buksa K, Gambuś H, Bojňanská T, Ivanišová E. Molecular Properties of selected polysaccharides determined by chromatography and their impact on water absorption of wheat flour. Potravinarstvo 2012;6:42-44. https://doi.org/10.5219/173.

95. Tungland BC, Meyer D. Nondigestible Oligo- and Polysaccharides (Dietary Fiber): Their Physiology and Role in Human Health and Food. Compr. Rev. Food Sci. Food Saf 2002;1:73-92. https://doi.org/10.1111/j.15414337.2002.tb00009.x 
96. Verbeken D, Dierckx S, Dewettinck K. Exudate gums: occurrence, production, and applications. Appl. Microbiol. Biotechnol 2003;63:10-21.

97. Williams PA, Phillips GO. Introduction to food hydrocolloids. In Handbook of Hydrocolloids, 2nd ed; Woodhead Publishing Limited 2000, 1-22.

98. Wood PJ. Relationships between solution properties of cereal $\beta$-glucans and physiological effects - a review. Trends Food Sci Technol 2004;15:313-320. https://doi.org/10.1016/j.tifs.2003.03.001.

99. Wood PJ. Cereal $\beta$-glucans in diet and health. J Cereal Sci 2007;46:230-238. https://doi.org/doi:10.1016/j.jcs.2007.06.012.

100.Xu X, Xu P, Ma C, Tang J, Zhang X. Gut microbiota, host health, and polysaccharides. Biotechnol. Adv 2013;31:318-37. https://doi.org/10.1016/j.biotechadv.2012.12.009.

101. Yamashita K, Kawai K, Itakura M. Effects of fructooligosaccharides on blood glucose and serum lipids in diabetic subjects. Nutr. Res 1984;4:961. https://doi.org/10.1016/S0271-5317 (84)80075-5

102.Yun JW. Fructooligosaccharides-Occurrence, preparation, and application. Enzyme Microb. Technol 1996;19:107-117. https://doi.org/10.1016/0141-0229 (95)00188-3.

103.Zhang SY, Li W, Smith CJ, Musa H. Cereal-derived arabinoxylans as biological response modifiers: Extraction, molecular features, and immune-stimulating properties. Crit. Rev. Food Sci. Nutr 2015;55:1033-1050. https://doi.org/10.1080/10408398.2012.705188.

104.Zhao D, Yu S, Sun B, Gao S, Guo S, Zhao K. Biomedical applications of chitosan and its derivative nanoparticles. Polymers 2018;462:1-17. https:// doi:10.3390/polym10040462.

105.Zhu Z, He J, Liu Barba G, Koubaa FJ, Ding M, Bals LO, Grimi N, Vorobiev E. Recent insights for the green recovery of inulin from plant food materials using nonconventional extraction technologies: A review. Innov. Food Sci. Emerg Technol 2016;33:1-9. https://doi.org/10.1016/j.ifset.2015.12.023. 